\title{
AUCTOR IN FABULA. MODOS Y FIGURAS DE LA AUTOALUSIÓN FÍLMICA
}

\author{
AUCTOR IN FABULA. MODES AND FIGURES \\ OF FILM SELF-ALUSION
}

\section{Imanol ZUMALDE ARREGUI}

Universidad del País Vasco / Euskal Herriko Unibertsitatea imanol.zumalde@ehu.eus

Resumen: Estas líneas analizan las múltiples formas mediante las que los cineastas se insertan y/o proyectan en sus películas, prolija fenomenología que se revisa mediante una serie de casos significativos (a saber: filmes que tematizan de manera ejemplar el hacer y/o la imagen de su creador) ordenados con arreglo a una taxonomía que hace inventario de las modalidades y figuras de la autoalusión fílmica.

Palabras clave: Autor. Autoalusión. Reflexividad. Cine. Filme.

Abstract: These lines analyze the multiple ways by which filmmakers are inserted and/or projected in their films. A complex phenomenology reviewed through a series of significant cases ordered according to a taxonomy that try to order and inventory the modalities and figures of cinematic self-reference.

Key Words: Author. Self-reference. Reflexivity. Cinema. Film. 


\section{INTRODUCCIÓN}

La semiótica siempre ha recelado del autor, así como del lector o del intérprete. De hecho, si algo distingue al modelo analítico de la semiótica estructural del resto de metodologías es que centra el foco en el texto en el convencimiento de que fuera de él, como afirmó Greimas, solo existe el abismo.

Para decirlo rápido, el mundo de la exégesis o de las metodologías de análisis está dividido en tres grandes espacios: a un lado están quienes consideran que lo que esas obras de arte significan responde sustancialmente a lo que su creador pensó mientras las hacía (las intenciones del autor), o incluso a lo que no pensó, pero vertió inconscientemente en ellas (las intenciones inconscientes). A otro lado se sitúan los que entienden que el texto lo es en plenas condiciones solo gracias a la intervención del lector que, con la lente de sus determinaciones intelectuales y sociológicas, lo actualiza otorgándole un sentido, de suerte que analizar un texto deviene en sociología de la recepción. Frente a estos enfoques, el análisis textual pone el acento en la autosuficiencia semiótica del texto, de modo que a la hora de llevar a cabo la exégesis no tiene en cuenta las intenciones creativas de su autor, ni las determinaciones sociohistóricas de sus lectores. O las tiene en cuenta de otra manera.

Lo que el análisis textual despeja de la ecuación de la exégesis son el autor y el lector empíricos, y los sustituye por el autor y lector modelos, que son figuras que se construyen (y habitan solo) en el discurso. Desde esta óptica, el autor no sería una persona o una figura sociohistórica, sino una entelequia o estrategia textual, un efecto de sentido inmanente generado por los propios discursos sobre su instancia creadora, sobre quien lo ha concebido. Esto está refrendado por el hecho de que la inmensa mayoría de los textos no hablan (de forma sustancial ni prioritaria) de su autor empírico, de sus peripecias biográficas ni de sus cuitas personales, sino que lo obvian para referirse a otras cosas, de modo que fundamentar su exégesis en esos aspectos no deja de ser una pérdida de tiempo.

De manera que el autor empírico se convierte de facto en una suerte de alteridad, en un agente extraño de naturaleza extradiscursiva que no cuenta para el exégeta semiótico, pero que está ahí, en el abismo greimasiano, merodeando en los aledaños del texto que ha creado, haciendo alarde de su presencia perturbadora, rascando la puerta como el 
lobo del cuento. Aunque quizá sea exagerado afirmar que desde una óptica semiótica el autor empírico es una otredad, no cabe duda de que hablamos de una figura problemática que la exégesis soslaya e ignora de palabra, pero con la que a veces ha de hacer cuentas de forma inevitable.

Hay obras, en efecto, en las que el autor empírico asoma o se persona advirtiendo a su interlocutor que ha de tenerle presente o en consideración a la hora de interpretar el texto que está leyendo. Es más, en ocasiones las obras exhiben marcas significantes que reclaman del contexto biográfico de su creador para su adecuada comprensión, de modo que el autor modelo se convierte en el avatar textual del autor empírico. Y esto, querámoslo o no, nos obliga a reconsiderar los términos de la relación de exclusión taxativa que hemos establecido con esa cristalización semiótica de la alteridad que es el autor empírico.

Y eso es lo que estas líneas analizan: las múltiples formas mediante las que los cineastas se insertan y/o proyectan en sus películas, fenomenología ciertamente prolija que se revisará mediante una serie de casos significativos (a saber: filmes que tematizan de manera ejemplar el hacer y/o la imagen de su creador) ordenados con arreglo a una clasificación que, atendiendo a su dispar morfología fílmica, hace inventario de las modalidades y figuras de la autoalusión.

Esta taxonomía, que siendo preliminar y tentativa queda al albur de ulteriores ajustes, se presenta ordenada de menor a mayor en función del grado de presencia y/o manifestación del autor. Así dispuesto se convierte en un inventario ascendente y, la mayor de las veces, acumulativo; es decir, la figura física del autor es a cada paso más explícita, y en muchas ocasiones procede por acumulación añadiendo o superponiendo la nueva maniobra o táctica autoalusiva a las anteriormente contempladas.

Antes de entrar en harina es necesario hacer una puntualización a propósito del concepto de autor cinematográfico que manejaremos aquí. A la estela de la noción acuñada en los años cincuenta del pasado siglo por los críticos de Cahiers du cinéma, consideraremos creador de la película a su director, a pesar de la inevitable arbitrariedad que entraña esta opción epistemológica en una obra como la cinematográfica de autoría empírica (casi) siempre plural. De cara a evitar suspicacias en este sentido, los ejemplos probatorios proceden en exclusiva del denominado cine de autor y han sido elegidos ad hoc entre los que exhiben una autoría individual 
incontrovertible. Así las cosas, la clasificación que se propone a renglón seguido resulta ser el inventario de los diversos procedimientos textuales mediante los que un sujeto de los muchos que participan en la creación material de una película se arroga o atribuye en exclusiva, para decirlo rápido, la responsabilidad estética de la obra.

\section{AUTOR EMPÍRICO IMPLÍCITO (O NO MANIFESTADO FÍSICAMENTE) QUE SE AUTODENOTA POR MEDIO DE DECISIONES DE PUESTA EN ESCENA}

Dicho de manera sucinta, esta categoría contempla aquellos casos en los que las elecciones formales denotan la intervención o la participación del director. Hablamos de una casuística potencialmente interminable dado que alude a toda decisión de puesta en escena, planificación, diseño sonoro, etc. que, al tiempo de contribuir al relato de la acción dramática, evidencia o pone en valor la voluntad (o el hacer creativo, por así decirlo) del autor. Sirvan dos ejemplos:

Centauros del desierto (The Searchers, John Ford, 1956) comienza con una pantalla en negro donde se abre una puerta en la que se recorta, al contraluz, la figura de una mujer de espaldas que no tarda en salir al luminoso exterior del desierto. Pues bien, el movimiento de la cámara que lo muestra precede un instante al de la mujer (en breve conoceremos que se llama Martha), como si la cámara propulsara al personaje, poniendo en marcha el relato y el drama. Sobre esa conspicua solución formal, que no constaba en el guion, Santos Zunzunegui afirma (2016: 30): "Martha sale al exterior empujada, literalmente, por una cámara que inscribe en ese gesto todo el saber del narrador sobre las determinaciones profundas de la historia".

El célebre comienzo de Ciudadano Kane (Citizen Kane, Orson Welles, 1940), en el que cuatro planos encadenados describen el vuelo de una cámara que, contra la prohibición que leemos en un cartel ("No traspassing"), salva el vallado de una mansión y entra furtivamente en terreno vedado, es toda una declaración de intenciones del autor o, si se prefiere, una metáfora de la actitud díscola, insumisa o contestataria respecto a la Institución y las reglas imperantes en Hollywood con la que el cineasta en ciernes (se trata de la escena inaugural de la opera prima de Welles) pone en marcha su filmografía. 
En ocasiones esta puesta en evidencia de la intencionalidad del director adquiere connotaciones políticas. Hablamos de opciones de puesta en escena y/o en imagen que "toman partido" poniéndose del lado (o en contra) de algún personaje (solidarizarse con su sufrimiento, hacerse cómplice de su hacer, etc.) A veces la gestión visual de lo que ocurre en la diégesis determina esa toma de postura del autor empírico (recuérdese lo dicho por Jacques Rivette [1960: 54-55] sobre del travelling de Kapo o las reiteradas proclamas de Jean-Luc Godard a propósito de que "los travellings son una cuestión moral"). A este respecto, hay cineastas que muestran sin medias tintas la crueldad, la violencia, lo abyecto (señalados trabajos de Michel Haneke y Ulrich Seidl van en esta línea), en tanto que otros "apartan la mirada del espectador" por una cuestión de pudor o moral (John Ford, por seguir con el ejemplo citado más arriba, elide el ataque indio en el que Martha es asesinada y, cuando los protagonistas lo encuentran, deja fuera de campo su cadáver).

La autocita sería otro procedimiento mediante el que el sujeto responsable de lo que vemos en pantalla se hacer notar (siendo estrictos, la autocita solo se daría cuando un sonido o una imagen determinada reaparecen en otro filme). Valga el ejemplo de Preludio de la guerra (Prelude to War, 1942) el primero de la serie de documentales propagandísticos de guerra Why We Fight, en el que entreverados con numeroso material de archivo Frank Capra reutilizó, con fines semánticos bien distintos, planos de sus recientes Caballero sin espada (Mr. Smith Goes to Washington,1939) y Juan Nadie (Meet John Doe, 1941).

Por su parte, las prácticas del remake (Leo McCarey en las dos versiones que filmó de Tú y yo - An Affair to Remember, 1939 y 1951-, por poner el caso) y la secuela (Vincente Minnelli en El padre de la novia Father of Bride, 1950- y El padre es abuelo -Father's Little Dividend, 1951—, por ejemplo), han sido propicias para toda suerte de florituras y variaciones autoalusivas que ponen en valor la voluntad, el hacer o la presencia tutora/creadora de los cineastas.

Para acabar, existen al margen de las anteriores otras formas de firmar una película, procedimientos eminentemente fílmicos mediante los que el autor deja su huella en el mundo que ha creado. El de los objetos hipersituados del cine de Yasujiro Ozu de los que hablan Thompson y Bordwell (1976: 64-66) es un caso elocuente. Valga el ejemplo de la tetera roja de Flores de equinoccio (Higanbana, 1958), objeto que aparece nada 
menos que en una veintena de planos de la película situado en diversas e inesperadas posiciones en la casa de los Hirayama, lo que la convierte no solo en una especie de hito topológico que ayuda al espectador a reconstruir la posición relativa que los diversos espacios de la acción mantienen entre sí, sino en una sofisticada (y divertida) forma de poner sobre la mesa la idea de la inteligencia creativa que sostiene el filme.

\section{APROPIACIÓN NOMINAL: EL AUTOR EMPÍRICO SE HACE PRESENTE POR MEDIO DE LA FIRMA (VÍA TÍTULOS DE CRÉDITO)}

Dos aspectos, en apariencia contradictorios, determinan toda reflexión a propósito de la rúbrica fílmica materializada en los títulos de crédito. En primer lugar, su obligatoriedad: por razones legales y sindicales es preceptivo señalar con nombres y apellidos a todos los que intervienen en las distintas fases que encadena la realización de la película, relación de coautores que ha de especificar el cometido de cada cual. Así, las cosas, la multitudinaria firma de los títulos de crédito pone en entredicho la naturaleza unipersonal de la autoría cinematográfica.

En segundo lugar, su disposición jerárquica o piramidal: la relación exhaustiva de los copartícipes en la realización de la película se expone ordenada jerárquicamente en función de la importancia de las tareas, de manera que el director del filme se sitúa en la cúspide de la pirámide de la autoría. Este escalafón diferencia, en primer lugar, los títulos de crédito de apertura y los de cierre, de modo que los primeros son una sinécdoque de qualité de los segundos (al final aparece la relación íntegra de los participantes, y al principio solo los responsables de las tareas más relevantes). En el seno de ambas rige el mismo orden jerárquico, pero se expone de manera inversa: en los títulos de crédito del comienzo la posición de privilegio del director se subraya, por regla general, dejándolo en último lugar (a saber: en la imagen que precede al comienzo propiamente dicho de la narración), mientras que en los del cierre su nombre encabeza esa multitudinaria firma con la que concluye la cinta.

La heterogénea casuística de los títulos de crédito merecería un estudio detallado que no emprenderemos aquí, de manera que solo podemos generalizar. Se trata, en resumidas cuentas, de advertir que hay casos en los que la alusión nominal al director, obligatoria y rutinaria per 
se, es sometida a un desplazamiento o torsión significativa con objeto de subrayarla por encina de las demás atribuciones nominales. En Hollywood, por ejemplo, algunos realizadores consiguieron el privilegio de que su nombre y apellidos aparecieran antes que el título de la película a modo de certificado de su estatuto creativo excepcional (Frank Capra, uno de ellos, tuvo sin duda en mente esa circunstancia cuando tituló su autobiografía The Name Above the Title).

Los créditos de arranque de Ciudadano Kane que preceden al opening autoalusivo descrito más arriba apuntan en esa dirección. Téngase en cuenta que, a raíz de su exitoso paso por la radio, Welles debutó en el cine siendo una estrella, razón que explica el presuntuoso aclarado del arranque en el que solo consta su nombre (tras el anagrama RKO, leemos "A Mercury Production .... by Orson Welles", donde el by está escrito con tipografía diferente que denota ser autógrafa, a lo que sigue sin solución de continuidad el título del filme). Entre las extravagancias nominales perpetradas en los títulos de crédito, se cuenta la de Avaricia (Greed, 1924), en los que Eric Von Stroheim se arroga todo el trabajo creativo que está detrás de la película no solo subrayando que lo dirige personalmente (el penúltimo cartón reza "Personally directed by Eric Von Stroheim", donde su nombre y apellido aparecen en letra cursiva), sino concluyendo los títulos de crédito con una extemporánea dedicatoria del filme a su madre.

\section{AUTOR EMPÍRICO QUE SE MANIFIESTA O EXPLICITA COMO PERSONAJE DIEGÉTICO}

Presenta modalidades distintas en función de la entidad del sujeto del enunciado que encarna el director:

\subsection{Personaje episódico dramáticamente irrelevante o no}

En estos casos el director aparece en escena como mero figurante o atrezo humano. En ocasiones la incursión puntual del director es gratuita o semánticamente inocua: la aparición de F. W. Murnau en la escena del baile de Amanecer (Sunrise, 1927) o los célebres cameos de Alfred Hitchcock serían casos paradigmáticos, aunque las irrupciones irónicas de Luis Buñuel en algunas de sus películas (como marista que pasa en 
bicicleta en La edad de oro —L'Age d'or, 1930—; sentado en la terraza del restaurante y como hombre con sombrero que pasa por una calle en Belle du jour, 1966; como fraile fusilado - junto a Serge Silberman y José Bergamín- en El fantasma de la libertad —Le Fantôme de la liberté, 1974 - etc.) no les andarían a la zaga.

Esa irrupción accidental o puntual de autor empírico puede sin embargo conllevar contrapartidas semánticas. Puede, por ejemplo, funcionar como signo de puntuación (o exhortación) de un relato que está dando cuenta de una historia que en ese preciso momento está a punto de experimentar un significativo cambio de registro. De manera que la aparición fugaz en cuadro de la efigie del autor empírico advierte al espectador de lo que se avecina (en cierta medida haría las veces de la figura del commentatore de la pintura clásica [cf. Calabrese, 2010: 70-74; Stoichita, 2009: 69-70]), al tiempo que deja sentado que el punto de giro en ciernes es fruto de su voluntad y omnipotencia enunciativa. Lo significativo en estos casos no es el hacer diegético del personaje encarnado por el autor empírico, sino el momento o el lance en el que este aparece en escena (su presencia, a veces entrevista, señala la importancia del acontecimiento inminente). Por ejemplo, los cameos Hitchcock en Vértigo (Vertigo, 1958) y Psicosis (Psycho, 1960), en el atrio de secuencia de la entrevista con el constructor y de la inmobiliaria, respectivamente, preludian escenas en las que se ponen las bases del drama o en marcha los engranajes de la acción. Aunque el ejemplo rey de esta subcategoría es la irrupción subrepticia (a la manera del criptorretrato o del ritratto dissimulato que señala Calabrese [2010: 49]) de Charles Chaplin en la secuencia de la estación de tren de Una mujer de París (A Woman of Paris, 1923).

Pero no siempre el hacer diegético del personaje episódico encarnado por el autor empírico es trivial o insignificante. Elevación al cubo de los cameos exhibicionistas de Hitchcock, los roles que acostumbra arrogarse M. Night Shyamalan en sus películas acometen, en efecto, una tarea crucial en la historia, tendencia que hace cumbre en Señales (Signs, 2002) donde interpreta al personaje que atropella y, por ende, mata a la mujer del protagonista. Este fatal acontecimiento no solo desencadena el drama del personaje principal (a saber: el sacerdote interpretado por Mel Gibson que además pierde la fe a causa del inexplicable accidente), sino que propicia que a la hora de la verdad este dé con la clave que le permitirá salvar a su familia (le facilita el saber que posibilitará matar in 
extremis al extraterrestre), y recupera la fe gracias a que por fin comprende el sentido o la función trascendental de la muerte propiciatoria de su mujer. Aun así, no se me ocurre caso más ejemplar de este supuesto que el de Luis Buñuel cortando con una navaja barbera el ojo de una mujer al comienzo de su opera prima El perro andaluz (Un chien andalou, 1927): situado en el frontispicio de su filmografía a modo de manifiesto inaugural o declaración de principios, constituye el destemplado anuncio de un proyecto vocacionalmente iconoclasta que echa a andar.

\subsection{Personaje relevante (secundario y protagonista)}

En estos casos el director encarna un rol de peso en el dramatis personae del filme, aunque sea un personaje secundario. En La joven del agua (Lady in the Water, 2006), Shyamalan va un poco más allá de lo habitual y sin llegar al extremo de apropiarse del papel protagonista (Paul Giamatti hace las veces del responsable de mantenimiento que protagoniza la historia), encarna al sujeto que escribe el libro que salvará al mundo en el futuro inmediato de la peripecia. En el quinto de los nueve cuentos de Boccaccio que adapta en Decameron (1971), Pier Paolo Pasolini interpreta a un discípulo de Giotto (situado a modo de Rubicón en el ecuador de este relato fragmentado, con este gesto de homenaje y reconocida deuda, el cineasta enuncia que es un narrador - Boccaccio - que maneja imágenes - Giotto-). En Sangre, sudor y lágrimas (In Which We Serve, 1942), Nöel Coward se mete en el papel del Capitán Kinross, personaje que en plena Segunda Guerra Mudial, cuando peor pintaban las cosas para la causa británica en los campos de batalla (el filme refleja en caliente el trauma del hundimiento del destructor H. M. S. Kelly bombardeado por los alemanes en la batalla de Creta), se hace portavoz de la indestructible voluntad de lucha británica en el discurso final. En Twin Peaks: The Return (2017), David Lynch interpreta al agente del FBI Gordon Cole, uno de tantos personajes que pululan por la serie; rol tangencial en las dos primeras temporadas que adquiere mayor relevancia en la tercera dado que con el paso del tiempo ha subido en el escalafón en la Agencia y se convierte en el encargado de la pesquisa de la desaparición del agente Cooper (sabe todo lo que ocurrió en el pasado; en todo caso más que cualquier otro personaje y que el propio espectador, que nunca termina de saber a ciencia cierta, ni infusa, lo que aconteció en torno a la muerte de Laura Palmer). 
En ocasiones, el propio director interpreta el personaje principal o protagonista, ostentosa modalidad de autoproyección que acredita variada casuística. Para empezar se encuentra el nutrido grupo de directores/ actores (por citar algunos de renombre: Eric Von Stroheim, Jerry Lewis, Clint Eastwood, Vittorio De Sica, Waren Beauty, Ben Affleck, George Clooney, Kevin Costner, Kenneth Branagh, Cristi Puiu, Emir Kusturica, Lena Dunham...) que interpretan el rol principal de algunas de sus películas de ficción, aunque este allanamiento de pantalla no entraña la mayor de las veces trasfondo semántico de enjundia. En otros casos, sin embargo, el autor empírico reivindica su figura de creador encarnando un personaje cuyas cualidades quiere arrogarse. El caso emblemático es el de François Truffaut en El pequeño salvaje (L'Enfant sauvage, 1969), cinta en la que el cineasta francés interpreta al educador, pedagogo y padre adoptivo que se hace cargo del indómito rapaz que da título al filme (como es sabido, Truffaut fue un huérfano funcional con notables problemas de socialización educado por su abuela, de suerte que en esta ficción encarna sintomáticamente la protectora figura paterna de la que careció en su infancia). Valga asimismo el caso de Ed Harris en Pollock. La vida de un creador (Pollock, 2003), en el que el director se mueve a todas luces con el propósito de atribuirse algunas cualidades que se le suponen al célebre creador del expresionismo abstracto (estaríamos ante la traslación cinematográfica del denominado "Autorretrato en persona histórica" de la pintura [cf. Calabrese, 2010: 85-123]).

Otra variante de interés, por último, es la de los actores/directores que, sin incurrir en la autobiografía que contemplaremos más adelante, modelan un personaje en el que se refracta su personalidad o actitud vital. Pienso en el segmento sonoro de la filmografía de Charles Chaplin, que supone un notorio cambio de registro respecto a sus películas de Charlot (Candilejas - Limelight, 1952 - y Un rey en Nueva York - A King in New York, 1957- son sin duda los más elocuentes en este sentido), en el profesor Pluggy, personaje demente y alborotado creado para sí mismo por Jean-Luc Godard que aparece, entre otras, en Nombre: Carmen (Prénom Carmen, 1983) y El rey Lear (King Lear, 1987), o en el puñado de películas de Woody Allen y Nanni Moretti en las que encarnan protagonistas facturados a su propia imagen y semejanza. 


\section{AUTOR EMPÍRICO QUE SE HACE CARGO DE LA NARRACIÓN}

El director de la película puede asumir tareas de narrador mediante varias fórmulas.

\subsection{Narrador exento}

En este supuesto el autor empírico no interpreta ningún personaje de la historia, sino solo labores de narración encarnando esa figura que en narratología se denomina narrador extradiegético. Esta modalidad puede adoptar dos formas genéricas:

Por un lado, está la de la voz creadora/fundadora, en la que el autor empírico se explicita como narrador por medio de su voz (hablaríamos de voice over autoral). Valgan tres ejemplos: en lugar de interpretar un personaje de la historia como en Citizen Kane, en su segundo largometraje (El cuarto mandamiento/The Magnificient Ambersons, 1942) Orson Welles se adjudicó la estratégica tarea de narrador del relato, de manera que los créditos que cierran la película, declamados por su estentórea e inimitable voz, concluyen con la frase: "My Name is Orson Welles". En Orfeo (1950), Jean Cocteau asume la voz narradora que pone en marcha el relato y, posteriormente, la voz de los mensajes provenientes de esa dimensión paralela a la realidad en la que se adentra el protagonista. En Banda aparte (Bande à part, 1964) y Dos o tres cosas que sé de ella (2 ou 3 choses que je sais d'elle, 1967), por poner dos ejemplos de un recurso recurrente en su filmografía, la susurrante voz de Godard se inmiscuye una y otra vez en el relato para hacer toda suerte de digresiones que ponen en evidencia su demiúrgico control del filme.

Por otra parte, hay que considerar al narrador de cuerpo presente, modalidad en la que el autor empírico ejerce de narrador extradiegético apareciendo también en cuadro. Valga el caso de Hitchcock que pudo en la pequeña pantalla dar rienda suelta a su irreprimible vis exhibicionista con fórmulas inaceptables por los estudios de Hollywood, entre las que ocupan destacado lugar las legendarias presentaciones y cierres de sus programas televisivos (Alfred Hitchcock Presents, 1955-1962, y Alfred Hitchcock's Hour, 1962-1965). En enfático homenaje al maestro del suspense, Lars Von Trier cierra todos los capítulos de sus dos temporadas de la teleserie 
Riget (1994 y 1997) irrumpiendo en cuadro (pero no en el espacio de la acción) con un paródico vis a vis con el espectador.

\subsection{Narrador diegetizado}

Supuesto en el que amén de la voz narradora, el autor empírico también encarna un personaje diegético llevando a la práctica la modalidad que la narratología denomina narrador intradiegético. En función del peso dramático del personaje en cuestión, este sincretismo entre sujeto de la enunciación y sujeto del enunciado admite al menos dos variantes:

\subsubsection{Narrador y protagonista}

En estos casos el filme espectaculariza el acto enunciativo con vistosas fórmulas, como la interpelación al espectador, que suponen cambios repentinos de nivel enunciativo o desembragues (el personaje pasa de ser el narrador que habla directamente al espectador, a personaje que interpreta su papel sin tener en cuenta al espectador, y viceversa). La vida por delante (1958) y La vida alrededor (1959), el díptico de Fernando Fernán-Gómez, la escena de la cola del cine de Annie Hall (1977) de Woody Allen o las digresiones de Charles Chaplin en Monsieur Verdoux (1947) constituyen aquilatados ejemplos de lo que estamos hablando, aunque ninguno alcanza el nivel de sofisticada autorreferencialidad hollado por los alambiques enunciativos de Sacha Guitry en los arranques de Le roman d'un tricheur (1936) y Desiré (1937).

\subsubsection{Narrador y personaje secundario o figurante}

Idéntico al supuesto anterior, pero concretado en un personaje secundario encarnado por el director de la película que hace las veces de narrador. Es el caso notorio de David Byrne en True Stories (1986) (en las postrimerías del cast de los títulos de crédito que cierran la película podemos leer "Narrated by David Byrne"). Al comienzo no es más que una voz en off que, a la manera de un filme ensayo, se sobrepone a una sucesión de imágenes hablando del estado de Texas, hasta que en un momento dado irrumpe al lado de esas imágenes (vemos que se proyectan en lo que parece la pantalla de un cine) y presenta al espectador a Virgil, el pueblo 
tejano donde transcurrirá la acción que todavía no ha comenzado. Cuando termina el parlamento proferido mirando a cámara, Byrne se sumerge en el espacio de la acción (de hecho, atraviesa materialmente la pantalla en la que se proyecta una imagen de la calle principal del pueblo). A partir de ahí, Byrne (quien a cada rato mira y habla directamente a cámara) hace de cicerone del espectador: nos presenta in situ los lugares y las gentes de Virgil, entre los que destaca Louis (interpretado por John Goodman), solterón que busca esposa cuya peripecia sobresale en el tapiz de historias que entreteje el filme.

\subsection{Autor endotópico}

Tomado de Victor I. Stoichita (2011: 401) que lo emplea para los cuadros que representan un artista manos a la obra donde "el pintor representado puede muy bien ser la misma persona que el autor del cuadro que estamos contemplando", aquí denominaría esos casos en los que el autor empírico encarna un personaje diegético que es un realizador que dirige un filme, de suerte que el argumento y la historia versan sobre la filmación de una película. El ejemplo más socorrido es el de François Truffaut en La noche americana (La nuit américaine, 1973), o el de JeanLuc Godard en El desprecio (Le mépris, 1967), donde encarna al ayudante de dirección de Fritz Lang, el verdadero realizador de la película cuyo accidentado rodaje refleja la peripecia del filme, aunque bien mirado estos casos no dejan de ser variantes elevadas de la categoría anterior (a saber: realizador que encarna personaje relevante). Para ser precisos aquí, en efecto, solo deberíamos contemplar los filmes netamente introspectivos como Roma (1972), cinta en la que Federico Fellini no solo aparece como director de la película que está rodando sobre la capital italiana, sino que también hace las veces de narrador en voice over que hace partícipe al espectador de los recuerdos y tortuosas cavilaciones que le suscita el escollo creativo de retratar su ciudad de adopción.

\section{RELATOS AUTOBIOGRÁFICOS}

Al margen de todo lo anterior, hay filmes cuya historia es reflejo más o menos estilizado de la andadura personal del autor empírico. Si esto diera pie a un relato autobiográfico a secas (como, por ejemplo, Dolor 
y gloria, 2019, de Pedro Almodóvar, donde su personaje está encarnado por Antonio Banderas), se trataría de una modalidad de la autolusión fílmica que se situaría en una posición previa (concretamente en la tercera categoría, antes del autor empírico que se explicita como personaje diegético) en el seno de esta clasificación dispuesta in cescendo. Sin embargo, esta autoproyección biográfica adquiere su quintaesencia en esos relatos fílmicos en los que el protagonista de la diégesis es interpretado por el sujeto real que vivió esos hechos; es decir, cuando el director del filme que narra su vida encarna en pantalla el rol principal.

No estoy pensando solo en los home movies ni en los usuarios más o menos afortunados de ese subgénero de la no ficción cinematográfica denominado ego-documental (sirva el caso de cineastas como Ross McElwee y Alan Berliner que han hecho de su existencia y de la de sus allegados la razón de ser de su filmografía), sino en un Sacha Guitry que en Mi padre tenía razón (Mon père avait raison, 1936) protagoniza una declarada autobiografía que rinde cuentas con su talentoso y abrasivo progenitor; o en Nani Moretti, que en la primera y segunda partes (de la tercera hablaremos en breve) de Caro diario (1993) saca a relucir sin pudor las filias y fobias que habitan en su vida cotidiana.

\section{7. ЕССЕ HOMO}

En la cúspide de la pirámide categorial de la autoalusión fílmica se encontrarían esa extraña suerte de películas biográficas del apartado anterior que, rizando el rizo de la autorreferencialidad, convierten a los avatares y vicisitudes corporales del autor empírico que encarna al protagonista en argumento troncal del relato. Traslación fílmica del Body Art, hablamos de obras que documentan la transformación que el tiempo de la diégesis (o la entropía del relato) infringe(n) en la anatomía del autor empírico. Se trata, no parece necesario insistir mucho en ello, de la modalidad más extrema y radical de autoalusión fílmica.

Super Size Me (2004) de Morgan Spurlock parece concebido como ejemplo de esta variedad paroxística de la autoría cinematográfica. Se trata, como es sabido, de un documental sobre la dieta del norteamericano medio expuesto a la denominada fast food. Amén de visitar escuelas públicas, entrevistar a ciudadanos con graves problemas de salud infringidos por la dieta, etc., el filme documenta (aporta sucesivas imágenes de su cambiante 
anatomía, análisis de sangre, electrocardiogramas, pruebas de esfuerzo, etc.) el progresivo deterioro del cuerpo del cineasta durante los treinta días de febrero de 2003 en los que se alimentó exclusivamente de comida de restaurantes MacDonalds. Aunque con un tono bien distinto, Nani Moretti se somete a un ejercicio parecido en "Médicos", la sobrecogedora tercera parte de Caro diario (1993), donde glosa su recorrido por especialistas y hospitales (aquí son las sucesivas recetas que le prescriben las que asoman en pantalla) a causa de un prurito que terminó siendo un cáncer cuyo tratamiento de radioterapia es mostrado con pelos y señales.

Con todo, y para terminar un tanto atropelladamente, no se me ocurre ejemplo más revelador de Ecce Homo que el ofrecido por Agnès Varda en sus últimos documentales. Compendio y summun de toda las modalidades de autoalusión filmica contempladas aquí, Los espigadores y la espigadora (Les glaneurs et la glaneuse, 2000) muestra a la manera de un corte geológico toda la tectónica de la autoalusión: Varda encarna a la narradora y protagonista de un documental que no solo ilustra su método de trabajo (recoge imágenes sobrantes, léase estampas de gente desahuciada/arrinconada por la sociedad, a la manera de una espigadora o de un clochard que escarba entre contenedores), sino que muestra su septuagenaria anatomía (rostro, manos, pelo, en primerísimo primer plano) convertida ya en ruina o deshecho. Uno de los argumentos mayores de este filme ontológicamente crepuscular estriba en la exhibición del oneroso peaje que el paso del tiempo se ha cobrado en el cuerpo de la autora.

\section{REFERENCIAS BIBLIOGRÁFICAS}

CALABRESE, O. (2010). L'arte dell'autoritratto. Storia e teoria di un genere pittorico. Firenze: VoLo publisher srl.

RIVETTE, J. (1961). "De l'abjection”. Cahiers du cinéma 120, 54-55.

STOICHITA, V. I. (2009). Cómo saborear un cuadro y otros estudios de historia del arte. Madrid: Cátedra.

(2011). La invención del cuadro. Arte, artífices y artificios en los orígenes de la pintura europea. Madrid: Cátedra.

THOMPSON, K. \& BORDWELL, D. (1976). "Space and Narrative in the Films of Ozu". Screen 198, 41-73. 
ZUNZUNEGUI, S. (2016). La mirada cercana. Microanálisis fílmico (edición revisada y ampliada). Santander: Shangrila.

Recibido el 2 de marzo de 2020.

Aceptado el 15 de abril de 2020. 